\title{
Economic impact of treatment for surgical site infections in cases of total knee arthroplasty in a tertiary public hospital in Brazil
}

\section{Authors}

Karine Dal-Paz ${ }^{1}$

Priscila RD Oliveira ${ }^{1}$ Adriana P de Paula ${ }^{1}$ Maria Cristina da S Emerick $^{2}$

José Ricardo Pécora ${ }^{3}$ Ana Lucia LM Lima

${ }^{1}$ Infections Service, Institute of Orthopedics and Traumatology, School of Medicine, Hospital das Clínicas, Universidade de São Paulo.

${ }^{2}$ Knee Group, Institute of Orthopedics and Traumatology, Hospital das Clínicas, Faculdade de Medicina da Universidade de São Paulo.

${ }^{3}$ Management Unit, Institute of Orthopedics and Traumatology, Hospital das Clínicas, Faculdade de Medicina da Universidade de São Paulo.
Submitted on: 03/08/2010 Approved on: 06/01/2010

Correspondence to: Ana Lucia L. M. Lima Rua Dr. Ovídio Pires de Campos, 333, Sala 311-A São Paulo - SP - Brazil CEP: 05403-010 Phone(Fax): +55-11-30696900 E-mail: ccih.iot@hcnet. usp.br

We declare no conflict of interest.

\begin{abstract}
The aim of this study was to estimate the additional cost of treatment of a group of nosocomial infections in a tertiary public hospital. A retrospective observational cohort study was conducted by means of analyzing the medical records of 34 patients with infection after total knee arthroplasty, diagnosed in 2006 and 2007, who met the criteria for nosocomial infection according to the Centers for Disease Control and Prevention. To estimate the direct costs of treatment for these patients, the following data were gathered: length of hospital stay, laboratory tests, imaging examinations, and surgical procedures performed. Their costs were estimated from the minimum values according to the Brazilian Medical Association. The estimated cost of the antibiotics used was also obtained. The total length of stay in the ward was 976 days, at a cost of US\$18,994.63, and, in the intensive care unit, it was 34 days at a cost of US\$ 5,031.37. Forty-two debridement procedures were performed, at a cost of US\$5,798.06, and 1965 tests (laboratory and imaging) were also performed, at a cost of US $\$ 15,359.25$. US $\$ 20,845.01$ was spent on antibiotics and US $\$ 1,735.16$ on vacuum assisted closure therapy, microsurgical flaps, implant removal, spacer use, and surgical revision. The total additional cost of these cases of hospital infection in 2006 and 2007 was of US\$ 91,843.75. Based on that, we demonstrate that the high cost of treatment for hospital infections emphasizes the importance of taking measures to prevent and control hospital infection.
\end{abstract}

Keywords: hospital acquired infection, surgery, costs.

[Braz J Infect Dis 2010;14(4):356-359] @Elsevier Editora Ltda.

\section{INTRODUCTION}

Nosocomial infections are an important problem for healthcare services worldwide. ${ }^{1}$ Every year, more than 18 million surgical procedures are performed in hospitals in the United States and it is estimated that $2.7 \%$ of these operations become complicated because of surgical site infection (SSI). ${ }^{2}$ SSIs account for 15 to $30 \%$ of all hospital infections $s^{3}$ and are associated with considerable morbidity and mortality and increased healthcare costs. ${ }^{4}$

According to the São Paulo Nosocomial Infection Studies and Control Association, ${ }^{5}$ it was observed in Brazilian tertiary hospitals in the 1990's that SSIs were the second most frequent type of infection (15.5\%) of all hospital infections described. During the same decade, SSIs occupied the same position in Spain and Greece, while in Swit- zerland they were the most prevalent type of infection. ${ }^{6}$ Prevention and control of SSIs are very important measures, given that such infections increase the length of hospital stay, causing additional burden of treatment and trouble for patients, such as emotional, physical, psychological, social and economic distress. ${ }^{7}$

Among the types of surgery currently performed, implantation of joint prostheses, particularly those of the hip and knee, is increasingly common. It has been estimated that 600,000 new hip and knee prostheses were implanted only in the United States in 2006. ${ }^{8}$ This type of procedure is subject to complications and, among them, infection is the most difficult to resolve. ${ }^{9}$ In cases of arthroplasties, SSIs are infections that may appear up to one year after the surgical procedure, whenever such infections can be correlated with the surgery. ${ }^{10}$ In a study 
conducted in England, the prevalence of SSIs was estimated as $0.65 \%$, among 15,792 total knee arthroplasty procedures. ${ }^{11}$

It is important to emphasize that the impact of nosocomial infections can be estimated through their repercussions on morbidity, mortality, and economic costs. Studies on the economic impact conducted in the United States and Europe have estimated that the cost of treatment for these infections is more than US $\$ 4$ billion a year. ${ }^{12}$

Evaluation of healthcare costs may involve three components: direct costs (prolongation of hospital stay, readmission, surgical procedures, medications, and laboratory tests); ${ }^{12}$ indirect costs (impaired quality of life, loss of productivity, etc.); and expenditure on primary healthcare. ${ }^{13}$ Some studies have quantified the impact of SSIs by analyzing the length of hospital stay and the direct costs of hospitalization for treatment of these infections. ${ }^{3,12}$

Hence, our study aimed to estimate the additional direct cost of treatment for a group of hospital infections in a tertiary public hospital in Brazil.

\section{MATERIAL AND METHODS}

This study was conducted at the Institute of Orthopedics and Traumatology of Hospital das Clínicas, at the School of Medicine of Universidade de São Paulo. This is a public tertiary-level teaching hospital with 150 beds. Over the study period, an average of 3,000 patients were seen per day, and around 500 orthopedic surgical procedures were performed per month.

This was a retrospective observational cohort study conducted by means of analyzing the medical records of 34 patients who developed infections after total knee arthroplasty diagnosed in 2006 and 2007. All patients included in this analysis had nosocomial infections related to the arthroplasty procedure, diagnosed according to the criteria of the Centers for Disease Control and Prevention (CDC). ${ }^{10}$ The Hospital Information and Management System software was used to search for the patients included in this study.

It was obtained the following information from each patient's medical records: age, gender, and preoperative risk classification according to the index of the American Society of Anesthesiologists. Information on readmission for treatment of infections related to the implant was also gathered: length of hospital stay, and subsidiary tests performed - including laboratory and imaging tests -, along with the surgical procedures and the antibiotics used.

The costs related to the length of hospital stay, the subsidiary examinations and the surgical procedures performed were estimated from the values suggested by the Brazilian Medical Association for the period of this research. The cost of the antibiotics used was obtained from the last purchase made by the hospital through a tendering procedure. This class of medications was chosen for the analysis because it is usually the most expensive prescription item on this teaching hospital.

The values obtained in Real, Brazilian currency, were converted into Dollar using the exchange rate of March 2008.

\section{DATA ANALYSIS}

The qualitative variables were represented by absolute frequencies (n) and relative frequencies (\%), and the quantitative variables, by means and standard deviations (SD).

\section{RESULTS}

The patients' mean age was $67.1 \pm 12.0$ years. There were 23 women $(67.6 \%)$ and 11 men $(32.4 \%)$. None of the patients had a preoperative risk assessment on the ASA scale of more than II (Table 1).

As shown in Table 2, to treat these cases of nosocomial infections required 976 days in hospital wards at total cost of US\$18,994.63, and 34 days in the intensive care unit at a cost of US\$5,031.37.

Over the study period, 1965 laboratory tests were performed, and the most frequent were: creatinine assays (157), serum urea assays (146), blood cell counts

Table 1. Epidemiological and clinical characteristics of studied patients

\begin{tabular}{cc|}
\hline \multicolumn{2}{|c|}{ Characteristics $(\mathbf{n}=\mathbf{3 4})$} \\
\hline Mean age (years) \pm SD & $67.1 \pm 12.0$ \\
\hline Female & $67.60 \%$ \\
\hline Male & $32.40 \%$ \\
\hline ASA* I $^{*}$ & $26.50 \%$ \\
\hline ASA II & $73.50 \%$ \\
\hline
\end{tabular}

*ASA, American Society of Anesthesiologists' score.

Table 2. Direct costs attributed to additional length of hospital stay to treat hospital infection after total knee arthroplasty

\begin{tabular}{|ccc|}
\hline $\begin{array}{c}\text { Additional length } \\
\text { of hospital stay }\end{array}$ & $\begin{array}{c}\text { Absolute } \\
\text { number (days) }\end{array}$ & Cost (US\$) \\
\hline Length of stay in ward & 976 & $18,994.63$ \\
\hline $\begin{array}{c}\text { Length of stay in } \\
\text { intensive care unit }\end{array}$ & 34 & $5,031.37$ \\
\hline Total cost (US\$) & - & $24,026.00$ \\
\hline
\end{tabular}


(146), platelet counts (152), serum sodium assays (135), serum potassium assays (137), and microbiological examinations, of which aerobic bacteria culture was the most common type (102). The average of the laboratories tests performed per patient was of 57.8 , thereby generating an additional cost of US\$15,359.24 (Table 3).

Table 3. The most frequent laboratory tests requested for patients with hospital infection after total knee arthroplasty

\begin{tabular}{cccc}
\hline Test & Quantity & $\begin{array}{c}\text { Unit price } \\
\text { (US\$) }\end{array}$ & Cost (US\$) \\
\hline Creatinine & 157 & 3.35 & 525.95 \\
\hline Urea & 146 & 3.35 & 489.10 \\
\hline Hemogram & 146 & 7.19 & $1,049.74$ \\
\hline Platelets & 152 & 2.40 & 364.80 \\
\hline Sodium & 135 & 3.35 & 452.25 \\
\hline Potassium & 137 & 3.35 & 458.95 \\
\hline Cultures & 102 & 28.75 & $2,932.50$ \\
\hline Total cost & - & - & $6,273.29$ \\
\hline
\end{tabular}

Regarding the medications used to treat these infections, an additional cost of US\$20,845.01 was estimated for the antibiotic therapy. The most used antimicrobial drugs were vancomycin and cefepime (Table 4).

Furthermore, 42 additional surgical procedures were required to treat these nosocomial infection patients. Some of these involved surgical debridement, vacuum assisted closure therapy, microsurgical flaps, implant removal, use of spacer, and two stages revision (Table 5).

The estimated additional cost attributed to these cases of hospital infection in 2006 and 2007 was of US\$ 91,843.75.

Table 4. The most frequent antimicrobial agents used in patients with hospital infection after total knee arthroplasty

\begin{tabular}{cccc}
\hline $\begin{array}{c}\text { Antimicrobial } \\
\text { agents }\end{array}$ & $\begin{array}{c}\text { Unit price } \\
\text { (US\$) }\end{array}$ & $\begin{array}{c}\text { Quantity } \\
\text { (flasks/ } \\
\text { ampoules) }\end{array}$ & Cost (US\$) \\
\hline Vancomycin & 1.79 & 1408 & $2,520.32$ \\
\hline Cefepime & 2.28 & 2000 & $4,560.00$ \\
\hline Teicoplanin & 18.14 & 483 & $8,761.62$ \\
\hline $\begin{array}{c}\text { Imipenem } \\
\text { + cilastatin }\end{array}$ & 10.72 & 240 & $2,572.80$ \\
\hline Ertapenem & 90.01 & 27 & $2,430.27$ \\
\hline Total & - & 4158 & $20,845.01$ \\
\hline
\end{tabular}

Table 5. Direct costs of laboratory tests and procedures used to treat hospital infections in cases of total knee arthroplasty

\begin{tabular}{|ccc|}
\hline Variables & $\begin{array}{c}\text { Absolute } \\
\text { number }\end{array}$ & $\begin{array}{c}\text { Cost } \\
\text { (US\$) }\end{array}$ \\
\hline Laboratory tests & 1965 & $15,359.25$ \\
\hline Surgical debridement & 42 & $5,798.06$ \\
\hline Vacuum assisted therapy & 5 & $1,735.16$ \\
\hline Microsurgical flap & 2 & 910.43 \\
\hline $\begin{array}{c}\text { Implant removal with } \\
\text { installation of spacer }\end{array}$ & 19 & $7,283.51$ \\
\hline Surgical revision & 2 & 527.09 \\
\hline Total cost & - & $31,613.50$ \\
\hline
\end{tabular}

\section{DISCUSSION}

The economic impact to manage the infected total knee arthroplasty reaches an annual amount of US\$ 300 million in the United States. ${ }^{9}$ Moreover, Stone (2005) found that SSIs on the hip may increase hospital stay to around 104 days and have an additional cost of US\$ 95,000. ${ }^{14}$ Another study conducted by Kirkland et al in $1999^{15}$ quantified the impact of the treatments for SSIs on 255 patients. The additional direct cost for the management of SSIs was of US\$ 5,038.00 per patient, and the total additional cost stemming from the SSIs over the study period was of US\$1,974,988.00. Another two studies estimated an additional cost per patient of US\$ $5,000.00$ for treatment of infected total knee arthroplasty ${ }^{7}$ and of US\$2,867.50 per patient with SSI in general. ${ }^{16}$

Most studies carried out to evaluate the economic impact of SSIs have used length of hospital stay as an indicator for the costs required for such infections. In studies conducted in different occasions between the 1950's and the beginning of the 1980's, the additional hospital stay attributed to SSIs was estimated to be between seven and 24 days. ${ }^{15}$ Studies conducted more recently have shown that SSIs could prolong the hospital stay by seven to 19.5 days, with an estimated cost of about US\$ 4,500 per patient. ${ }^{3,12}$

The use of the direct costs of hospitalization has been suggested as the best method to estimate the costs of hospital related infections, since they represent the real costs to the hospital for the items and services used by each patient. Unfortunately, however, this method may underestimate the total expenditure and also underestimate the financial and personal impact on the patients themselves (indirect costs). ${ }^{15}$

In accordance with previous studies, our study showed that the cost of treatment for SSIs is extremely high. The additional direct costs to treat infections of total knee arthroplasty were of US\$ $91,843.75$ as whole, and US\$ 2,701.29 per patient. 
It is important to highlight some aspects in this study. The method used did not take into account any assessment of indirect costs, and expenditures were surveyed using a database that presents the minimum costs for the procedures evaluated. Thus, the costs for the treatment of this group of nosocomial infections may be even higher than the one presented here.

Based on the high cost of the treatment for hospital related infections demonstrated in the present study, it is important to point out the relevance of implementing measures to prevent and control nosocomial infections.

\section{REFERENCES}

1. Izquierdo-Cubas F, Zambrano A, Frometa I et al. National Prevalence of Nosocomial Infections. Cuba 2004. J Hosp Infect 2008; 68:234-40.

2. National Nosocomial Infections Surveillance System. Semiannual Report. Centers for Disease Control and Prevention: Atlanta, 1996.

3. Maksimovic J, Marković-Denić L, Bumbaširević M et al. Surgical Site Infections in Orthopedic Patients: Prospective Cohort Study. Croat Med J 2008; 49:58-65.

4. Wilson J, Charlett A, Leong G et al. Rates of surgical site infection after hip replacement as a hospital performance indicator: analysis of data from the English Mandatory Surveillance System. Infect Control Hosp Epidemiol 2008; 29:219-26.

5. Associação Paulista de estudos e Controle de Infecção Hospitalar. Prevenção da infecção de Sítio Cirúrgico. 2a Edição, 2001.

6. Centers for Disease Control and Prevention. The National Healthcare Safety Network (NHSN) Manual. Patient Safety Component Protocol. Division of Healthcare Quality Promotion National Center for Infections Diseases, Atlanta, Georgia, 2007.
7. Whitehouse NDF, Kirkland KB, Richardson WJ, Sexton DJ. The impact of surgical-site infections following orthopedic surgery at a community hospital and a university hospital: adverse quality of life, excess length of stay, and extra cost. Infect Control Hosp Epidemiol 2002; 23:183-9.

8. Del Pozo JL, Patel R. Infection Associated with Prosthetic Joints. New Engl J Med 2009; 361:787-94.

9. Lima ALLM, Pécora JR, Albuquerque RM et al. Infection following total knee joint arthroplasty: considerations and treatment. Acta Ortop Bras 2004; 12:236-41.

10. Mangram AJ, Horan TC, Pearson ML, Silver LC, Jarvis WR. The Hospital Infection Control Practices Advisory Committee. Guideline for Prevention of Surgical Site Infection. Infect Control and Hosp Epidemiol 1999; 20:247-78.

11. Health Protection Agency. Mandatory surveillance of surgical site infection in orthopaedic surgery: April 2004 to March 2005. London: Health Protection Agency, 2005.

12. Coello R, Glenister H, Fererest J et al. The cost of infection in surgical patients: a case-control study. J Hosp Infect 1993; 25:239-50.

13. Reilly J, Twaddley S, McIntoshz J, Kean L. An economic analysis of surgical wound infection. J Hosp Infect 2001; 49:245-9.

14. Stone PW, Hedblom EC, Murphy D, Miller SB. The economic impact of infection control: Making the business case for increased infection control resources. Am J Infect Control 2005; 33:542-7.

15. Kirkland KB, Briggs JP, Trivette SL, Wilkinson WE, Sexton DJ. The impact of surgical-site infections in the 1990: attributable mortality, excess length of hospitalization and extra costs. Infect Control Hosp Epidemiol 1999; 20:725-30.

16. Defez C, Fabbro-Peray P, Cazaban M, Boudemaghe T, Sotto A, Daurès JP. Additional direct medical costs of nosocomial infections: estimation from a cohort of patients in a French university hospital. J Hosp Infect 2008; 68:130-6. 